\title{
HEAT AND MASS TRANSFER PREDICTIVE 3D MODEL OF MANGO KERNEL DURING CONVECTION OVEN DRYING PROCESS
}

\author{
Md. Shafiul Islam, Md. Sumon Ali, Mohammad Nurur Rahman and Pabitra Chandra Das* \\ Department of Chemical \& Food Process Engineering, Rajshahi University of Engineering \& \\ Technology (RUET), Rajshahi-6204, Bangladesh
}

\begin{abstract}
A large number of mangoes are utilized in process industries which produce a large amount of mango kernel that can be utilized effectively as a by-product. Processing and utilization of mango kernel flour is getting more scientific interest day by day. Drying is one of the major operations of flour processing where the moisture loss and heat transfer phenomena across the different portions of the products have to be pre-defined for better drying accuracy. The study was conducted to define a compatible predictive model that represents a $3 \mathrm{D}$ expression of heat penetration through the mango kernel slice (MKS) and moisture losses during drying with convective oven dryer using COMSOL Multiphysics with originated boundary conditions, excluding the changes of properties due to varying mangoes species. The model was validated using a convective drying process for varying thicknesses 4,6 and $8 \mathrm{~mm}$ of MKSs having temperature elevated to $60^{\circ} \mathrm{C}$ and $1 \mathrm{~ms}^{-1}$ air velocity up to $5 \mathrm{hr}$. The developed model was concurred and correlated well with the experimental data and can be used in describing heat and mass transfer phenomena while drying the mango kernel.
\end{abstract}

\section{Introduction}

Mangoes (Mangifera indica L.) are one of the most common seasonal fruits in Bangladesh, is considered as the "king of fruits". Food and Agriculture Organization (FAO) of the United Nations reported that around 2.4 million tons of mangoes were harvested in 2017-18 financial year and it has been increased 16 percent per year [1]. A large number of food processing industries are producing mango pulp, juice, jam, jelly, extract etc, where mangos are the prime raw materials.

A whole mango contains around $66.10-72 \%$ pulp, $9.80-14.30 \%$ peel, $8.8-12.4 \%$ inedible kernel and $7.50-9.30 \%$ seed coat [2]. The inedible mango kernels have appeared as waste which can cause environmental, hygienic, and public health problems result in inadequate management of this waste $[3,4]$. On the contrary, these mango kernels are nourished with carbohydrates $(58-80 \%)$ and protein (6-13\%) [2]. It is reported that the inedible kernel has $69.22 \%-79.78 \%$ carbohydrase, 8.35$16.13 \%$ fat, $5.6-9.5 \%$ protein, and $0.35-3.66 \%$ ash [5].

In recent years, the utilization of mango seed kernel has been getting much popularity to the scientists. Production of mango kernel flour supplemented food, mango kernel oil, extraction of different bioactive compounds and anti-oxidants are the common uses of mango kernel [6-8].
Drying is an essential step of mango kernel processing and preservation that reduce water content, destroy many deteriorating active compounds and limit microbial activities [9]. It is important to evaluate an appropriate mechanism of drying to understand and control the process, and also for the establishment of improved design guidelines [10].

Several experimental and theoretical studies have been conducted to analyze the drying properties of mango kernels under various conditions. This study is aimed to develop a 3D model that can be able to describe the heat and mass transfer phenomena for different thicknesses of mango kernels. The following section of this study calculates the parameters required to originate appropriate boundary conditions. After that, it produces the 3D model using COMSOL Multiphysics and also compares model for validation of drying with experimental data.

\section{Mathematical Model}

The mathematical model was developed for three difference thickness $(4,6,8 \mathrm{~mm})$ of mango kernel. To simulate this model, the input parameters are calculated and collected after considering some assumptions. 


\subsection{Assumptions}

Following assumptions were considered for model development $[11,12]$ :

1. The considered sample is a homogenous matter

2. The migration of moisture to the surface follows a diffusion mechanism.

3. The velocity and properties of supplied air are constant and laminar flow.

4. Having small thicknesses of the sample, two-dimensional equations are adequate.

5. The initial temperature and moisture content over the sample is uniformly distributed.

\subsection{Governing Equations}

\subsubsection{Heat Transfer}

The Fourier flux equation for heat transfer of the mango kernel is following [13]:

$$
\rho \mathrm{Cp} \frac{\delta T}{\delta t}=\nabla \cdot(k \nabla T)+Q
$$

here, $\rho$ is the density of sample $\left(\mathrm{kg} / \mathrm{m}^{3}\right), \mathrm{C}_{\mathrm{P}}$ is the specific heat $\left(\mathrm{Jkg}^{-1} \mathrm{~K}^{-1}\right), \mathrm{T}$ is the temperature $(\mathrm{K})$, and $\mathrm{k}$ is the thermal conductivity $\left(\mathrm{Wm}^{-1} \mathrm{~K}^{-1}\right)$. The value of heat generation, $\mathrm{Q}\left(\mathrm{Wm}^{-1}\right)$ is null since no heat generation inside the food materials. Thus, the expression changes to [14],

$$
\rho \mathrm{Cp} \frac{\delta T}{\delta t}=\nabla \cdot(k \nabla T)
$$

\subsubsection{Mass Transfer}

According to the assumptions, the mass balance equation follows Fick's law of diffusion [15]:

$$
\nabla \cdot(-D \nabla c)+\frac{\delta c}{\delta t}=0
$$

here, $\mathrm{c}$ is the moisture concentration $\left(\mathrm{mol} / \mathrm{m}^{3}\right), \mathrm{t}$ is the time (s) and D is the moisture diffusivity.

\section{Simulation Procedure}

\subsection{Input Parameters}

The required input parameters for the modeling were calculated with the corresponding equations.

\subsubsection{Heat Capacity}

Heat capacity was calculated using the following expression proposed for food product by Heldman and Singh [16],
$C p=1.424 X h+1.549 X p+1.675 X f+0.837 X a+4.187 X w$

here, $\mathrm{C}_{\mathrm{p}}$ is the heat capacity $\left(\mathrm{KJkg}^{-1} \mathrm{~K}^{-1}\right)$, and $\mathrm{Xh}$, $\mathrm{Xp}, \mathrm{Xf}, \mathrm{Xa}$ amd $\mathrm{Xw}$ are the mass fractions of carbohydrate, protein, fat, ash and moisture respectively.

\subsubsection{Thermal Conductivity}

The proposed equation by Sweart (1986) for thermal conductivity is as follows [16],

$K=0.2 X h+0.155 X p+0.16 X f+0.135 X a+0.58 X w$

here, $\mathrm{K}$ is the thermal conductivity $\left(\mathrm{Wm}^{-1} \mathrm{~K}^{-1}\right)$ and the mass fractions are described in section 3.1.1.

\subsubsection{Heat Transfer Coefficient}

The heat transfer coefficient was calculated from Nusselt number $(\mathrm{Nu})$ by using the following expression [17],

$$
\mathrm{Nu}=(\mathrm{hL}) / \mathrm{K}=0.664 \operatorname{Re}^{0.5} \operatorname{Pr}^{0.33}
$$

where, $\mathrm{h}$ is the heat transfer coefficient $\left(\mathrm{Wm}^{-1} \mathrm{~K}^{-1}\right)$, $\mathrm{L}$ is the characteristic length and $\mathrm{Re}, \mathrm{Pr}, \mathrm{Sc}$ are the Reynold, Prandtl Sherwood numbers respectively.

\subsubsection{Mass Transfer Coefficient}

The mass transfer coefficient was calculated by determining Schmidt number (Sc) and Sherwood number (Sh) with the following expression [17],

$$
\mathrm{Sh}=\left(\mathrm{h}_{\mathrm{m}} \mathrm{L} / \mathrm{D}\right)=0.664 \mathrm{Re}^{0.5} \mathrm{Sc}^{0.33}
$$

where, $\mathrm{h}_{\mathrm{m}}$ is the mass transfer coefficient $\left(\mathrm{kgm}^{-2} \mathrm{~s}^{-1}\right)$

The calculated and obtained parameters as input variables for the COMSOL Multiphysics are tabulated in the Table 1.

\subsection{Materials Properties}

The value of thermal conductivity, density and heat capacity is required to add a new material to simulate. The obtained value of heat capacity was $1248.9 \mathrm{Jkg}^{-1} \mathrm{~K}^{-1}$ and thermal conductivity 0.2636 $\mathrm{Wm}^{-1} \mathrm{k}^{-1}$

\subsection{Geometry}

A two-dimensional $6 \times 20 \mathrm{~mm}$ length rectangle has drawn having axial symmetry on ad axis (Fig. 1). Since the samples were kept on a drying tray, there was no heat transfer due to convection through the cd length and another whole surface was exposed to convective heat transfer. 
Table 1:

Input Properties in the Model

\begin{tabular}{lccc}
\hline Parameter & Variable Name & Value & References \\
\hline Drying air temperature & $\mathrm{T}_{\mathrm{o}}$ & $65^{\circ} \mathrm{C}$ & This Study \\
Initial temperature of Mango Kernel & $\mathrm{T}$ & $20^{\circ} \mathrm{C}$ & This Study \\
Density of Mango Kernel & $\rho$ & $912 \mathrm{~kg} / \mathrm{m}^{3}$ & {$[18]$} \\
Heat Transfer coefficient & $\mathrm{h}_{\mathrm{T}}$ & $274.5 \mathrm{w} /\left(\mathrm{m}^{2} \mathrm{k}\right)$ & Calculated \\
Molecular weight of Water & $\mathrm{M}$ & $0.018 \mathrm{~kg} / \mathrm{mol}$ & - \\
Initial moisture content & $\mathrm{c}_{\mathrm{o}}$ & $24720.2267 \mathrm{~mol} / \mathrm{m}^{3}$ & This Study \\
Drying air moisture concentration & $\mathrm{c}$ & $1012.22 \mathrm{~mol} / \mathrm{m}^{3}$ & Calculated \\
Specific moisture capacity & $\mathrm{c}_{\mathrm{m}}$ & 0.003 & {$[6]$} \\
Moisture conductivity & $\mathrm{k}_{\mathrm{m}}$ & $8.363 \times 10^{-3} \mathrm{Kg} /(\mathrm{ms})$ & Calculated \\
Mass transfer coefficient & $\mathrm{h}_{\mathrm{m}}$ & $546.314 \mathrm{~kg} /\left(\mathrm{m}^{2} \mathrm{~s}\right)$ & Calculated \\
Diffusion coefficient & $\mathrm{D}$ & $2.16 \times 10^{-5} \mathrm{~m}^{2} / \mathrm{s}$ & Calculated \\
Molar latent heat of vaporization & $\mathrm{I}_{\mathrm{da}}$ & $41400 \mathrm{~J} / \mathrm{mol}$ & Calculated \\
\hline
\end{tabular}

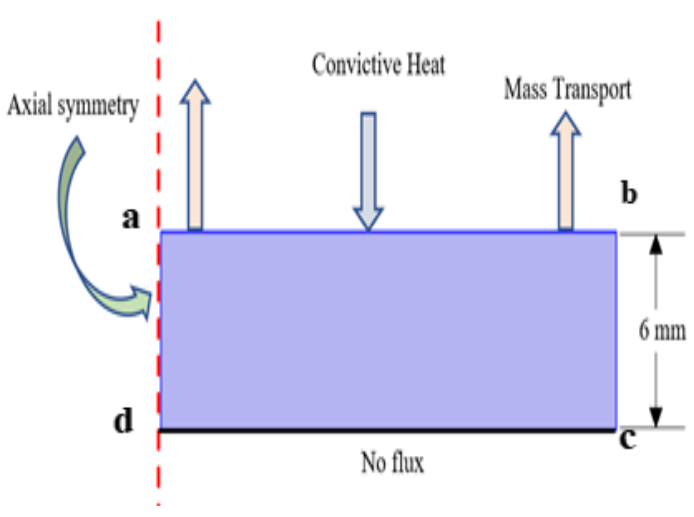

Fig. 1: Geometry of 6 mm MKS sample

\subsection{Boundary Conditions}

For heat transfer, the initial product temperature (To) and for the transport of diluted species, initial concentration (Co) of water molecules was added. For heat and mass transfer, boundary heat source and heat flux were added.

\section{Results and Discussions}

\subsection{Mass Transfer Prediction and Validation}

The predicted model provided the moisture concentration profile of MKS for three different thicknesses $4 \mathrm{~mm}, 6 \mathrm{~mm}$ and $8 \mathrm{~mm}$ with the drying temperature up to $5 \mathrm{hr}$. In this model the results of moisture concentration have found along with a different portion of the MKS for each of the 30 minutes interval. It was found that the lowest molecular concentration at the surface of the MKSs was $1.01 \times 10^{3} \mathrm{~mol} / \mathrm{m}^{3}$ according the developed - model (Fig. 2, 3 and 4). Changes in molecular concentration was noticed with the increasing of drying time such as $1.68 \times 10^{4} \mathrm{~mol} / \mathrm{m}^{3}$ and $9.12 \times 10^{3}$ $\mathrm{mol} / \mathrm{m}^{3}$ for 2.5 hours and $5 \mathrm{hr}$ drying, respectively, in the center of $4 \mathrm{~mm}$ thicken MKS (Fig. 2).

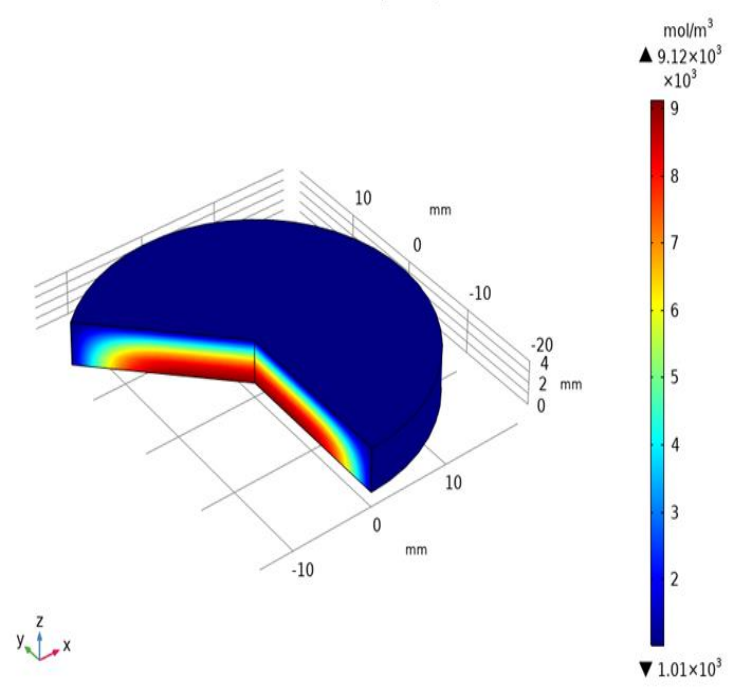

Fig. 2: Moisture concentration profile of $4 \mathrm{~mm}$ thickness MKS (at $60{ }^{\circ} \mathrm{C}$ for $5 \mathrm{hr}$ )

Fig. 3 and Fig. 4 show the moisture concentration profile of the $6 \mathrm{~mm}$ and $8 \mathrm{~mm}$ thickness MKS sample, respectively, simulated for drying at $60{ }^{\circ} \mathrm{C}$ for $5 \mathrm{hr}$. The highest moisture concentration of $1.79 \times 10^{4} \mathrm{~mol} / \mathrm{m}^{3}$ was found at the centre of the sample for $6 \mathrm{~mm}$ MKS. On the other hand, the centre moisture concentration for $8 \mathrm{~mm}$ thick MKS was $2.68 \times 10^{4} \mathrm{~mol} / \mathrm{m}^{3}$ after $5 \mathrm{hr}$ of drying. In figure 5 , a comparative plot was illustrated of moisture concentration for different thicknesses of MKS sample at the centre and surface obtained after 2.5 $\mathrm{hr}$ and $5 \mathrm{hr}$ drying. It was found that the mostly 
thick mango kernel $(8 \mathrm{~mm})$ had the highest molecular moisture concentration and indicated that less moisture is removed from a thicken sample at same time and temperature of drying.

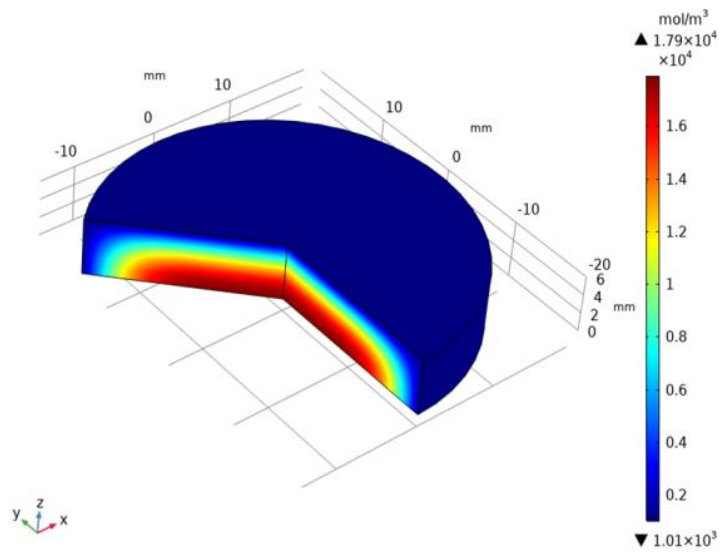

Fig. 3: Moisture concentration profile of $6 \mathrm{~mm}$ thickness MKS (at $60{ }^{\circ} \mathrm{C}$ for $5 \mathrm{hr}$ )

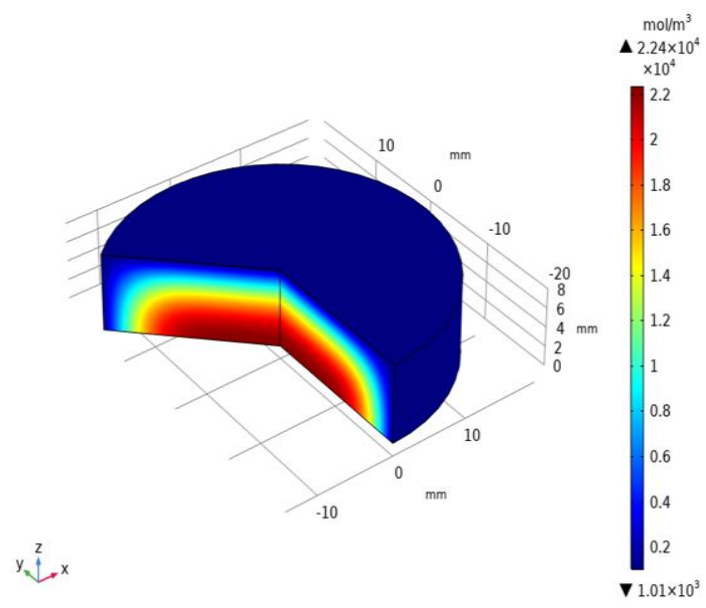

Fig. 4: Moisture Concentration profile of $8 \mathrm{~mm}$ thickness MKS (at $60{ }^{\circ} \mathrm{C}$ for $5 \mathrm{hr}$ )

The simulated data were validated with the data obtained from the experimental study. In this concern, $4 \mathrm{~mm}$ thick mango kernel slices were subjected to drying by using a convective oven dryer at a temperature of $60{ }^{\circ} \mathrm{C}$ up to $5 \mathrm{hr}$ at an interval of $1 \mathrm{hr}$. The loss of weight due to drying was recorded and the moisture content at each interval was calculated. Finally, the data of molecular moisture concentration were calculated from moisture values. Fig. 6 shows the correlation between the modeled and experimental results, where the correlation coefficient was 0.995174, which significantly means a well correlated. In most cases, the sample to be dried, kept on a metallic tray that also provides heat to the product. In this case, the tray was not considered and some change in formulated value has found. Invalidation of the model moisture concentration relatively lower than the experimental value. It might be happened due to the conductive heat provided by the drying tray did not consider.

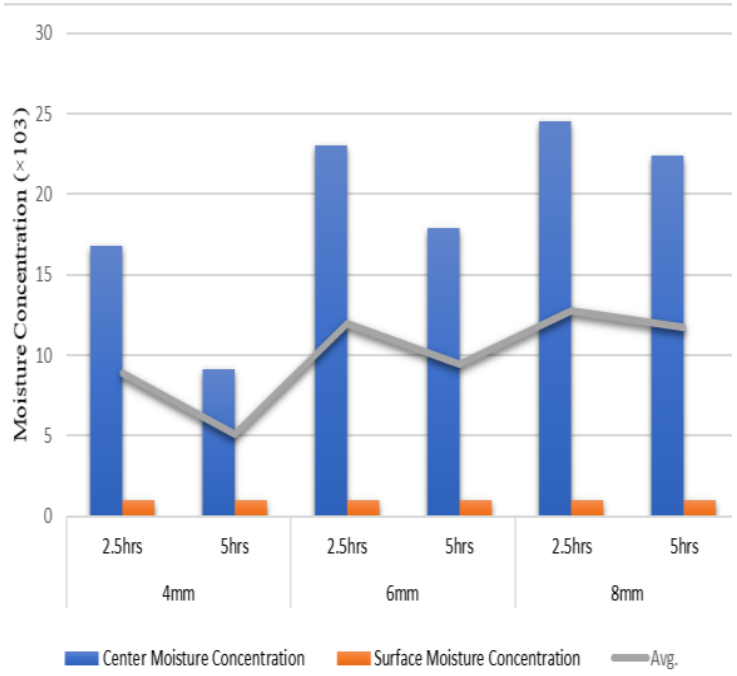

Fig. 5: Moisture Concentration of different thicknesses of MKS with surface and center temperature

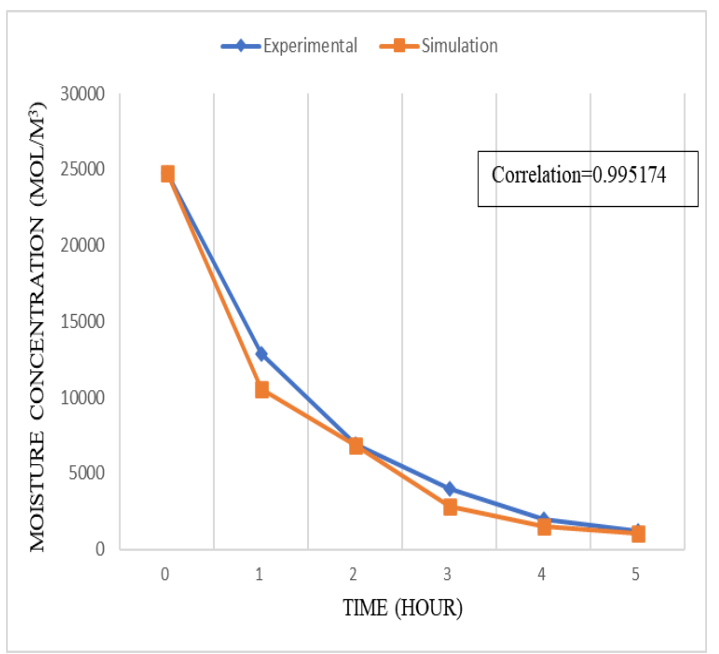

Fig. 6: Comparison between experimental and simulation result for $4 \mathrm{~mm}$ thickness MKS

\subsection{Heat Transfer Prediction}

The convective heat penetrates the MKS sample through the surfaces exposed to the air. Change of heat penetration showed in Fig. 7 for the interval of $2.5 \mathrm{hr}$ drying. At the center of sample, the temperature raised $59.5{ }^{\circ} \mathrm{C}$ after $2.5 \mathrm{hr}$ and $59.7^{\circ} \mathrm{C}$ after $5 \mathrm{hr}$ drying for $4 \mathrm{~mm}$ thickness sample.

The maximum achieved temperature at the center of MKS slightly was varied with thicknesses of the sample as shown in Fig. 8. 

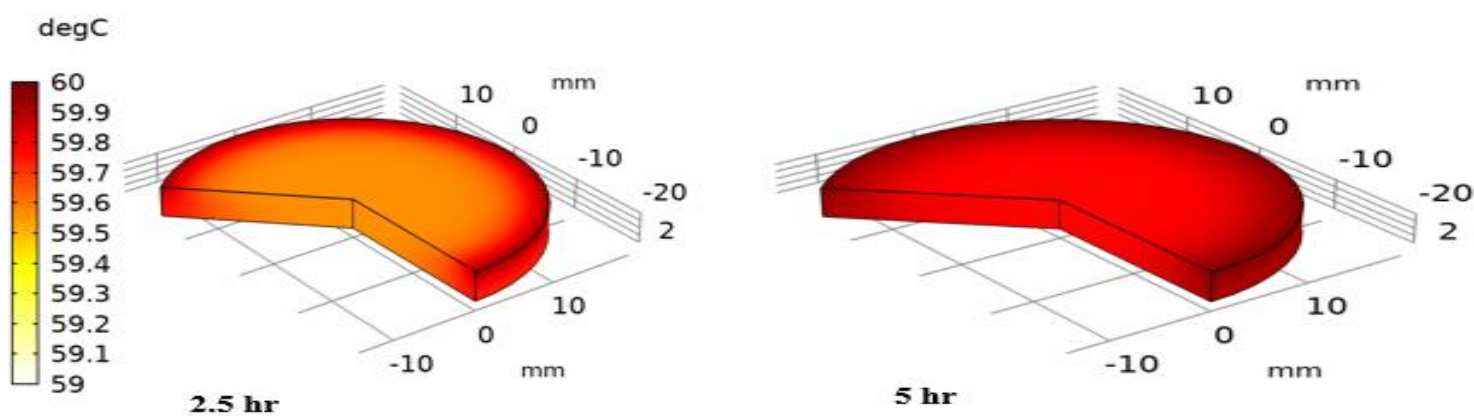

$2.5 \mathrm{hr}$

$5 \mathrm{hr}$

Fig. 7: Heat Transfer prediction of $4 \mathrm{~mm}$ MKS sample
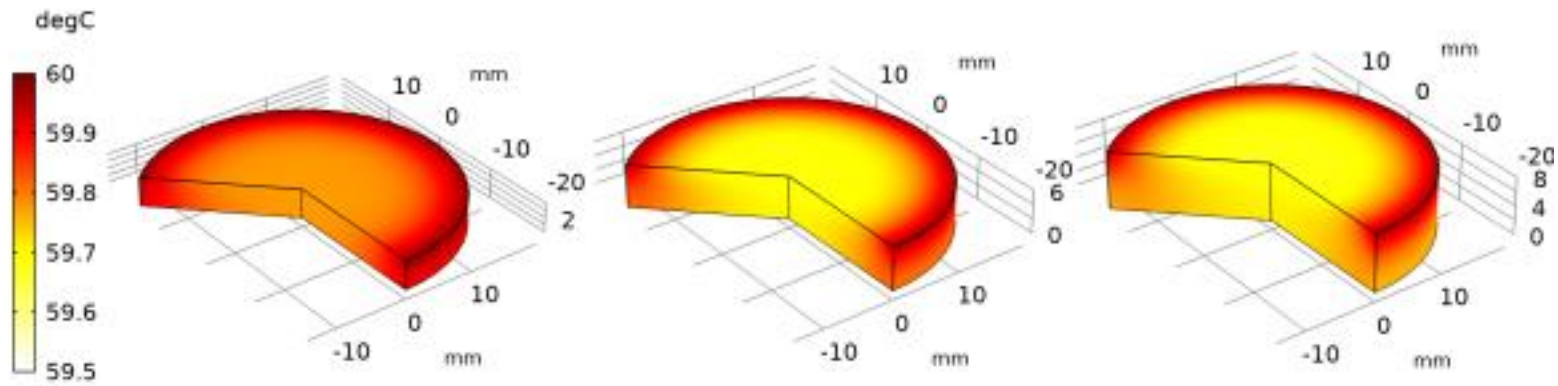

Fig. 8: Temperature profile of different thicknesses MKS dried at $60^{\circ} \mathrm{C}$ up to $5 \mathrm{hrs}$

The center temperature of $6 \mathrm{~mm}$ and $8 \mathrm{~mm}$ thicknesses MKS sample were almost the same and it was about $59.68^{\circ} \mathrm{C}$ after $5 \mathrm{hr}$ of drying. The temperature difference between surface and center was very low, which implies that the applied drying air temperature was uniformly distributed in the different portions of MKS.

\section{Conclusions}

A comprehensive model of heat and mass transportation during convective drying of mango kernel was formulated. This model showed its ability to predict molecular transportation and heat distributions with changing drying temperature, thickness and other dominating parameters. This model has been formulated for a single slice of mango kernel slice, so that these phenomena will be changes for industrial large scale drying process.

\section{Acknowledgments}

This work acknowledges department of Chemical \& Food Process Engineering, Rajshahi University of Engineering \& Technology (RUET) for supporting us.

\section{References}

[1] Mahmud, I. Bangladesh's growing success in fruit production. The Prothom-Alo English [Online]. 9 May, 2019. viewed 11 October, 2020, <https://en.prothomalo.com/bangladesh/Bangladeshs-growing-success-in-fruit-production>

[2] Das, P. C., Sattar, S., Jony, M. E. and Islam, M. N. (2018), Rehydration kinetics of flour from dehydrated mango kernel, Food Research, 2(5), pp. 474-480

[3] Ashoush I., Gadallah M. (2011), Utilization of mango peels and seed kernels powders as sources of photochemicals in biscuit, World J Dairy \& Food Sciences, 6(1), pp. 35-42

[4] Dorta E., Gloria M. (2012), Using drying treatments to stabilize mango peel and seed: effect on antioxidant activity, LWT Food Sci Technol 45, pp. 261-268

[5] Dhingra S., Kapoor A. C. (1985). Nutritive value of mango seed kernel, Journal of the Science of Food and Agriculture, 36(8), pp. 752-756

[6] Abdalla A. E. M., Darwish S. M., Ayad E. H. E., ElHamahmy R. M. (2007), Egyptian mango byproduct 1: compositional quality of mango seed kernel, Food Chemistry, 103(4), pp. 1134-1140

[7] Nzikou J.M., Kimbonguila A., Matos L., Loumouamou B., Pambou-Tobi N. P. G., Ndangui C. B., Abena A. A., Silou T. H., Scher J., Desobry S. (2010), Extraction and characteristics of seed kernel oil from mango (Mangifera indica), Res $J$ Environmental and Earth Science, 2(1), pp. 31-35 
[8] Das, P.C., Khan J., Rahman M.S., Majumder S. and Islam M.N. (2019). Comparison of the physicochemical and functional properties of mango kernel flour with wheat flour and development of mango kernel flour based composite cakes. NFS Journal, 17, 1-7. https://doi.org/10.1016/j.nfs.2019.10.001

[9] Dorta E., Lobo M. G., Gonzalez M. (2012), Using drying treatments to stabilise mango peel and seed: Effect on antioxidant activity, LWT - Food Science and Technology, 45, pp. 261-268

[10] Haghighi K., Segerlind L. J. (1998), Failure of Biomaterials Subjected to Temperature and Moisture Gradients Using the Finite Element Method: II Stress Analysis of an Isotropic Sphere during Drying, American Society of Agricultural and Biological Engineers, 31(3), pp. 0938-0946

[11] Khan M. I. H., Kumar C., Joardder M. U. H., Karim M. A. (2016), Determination of appropriate effective diffusivity for different food materials, Drying Technology, 35, pp. 335-346

[12] Joardder M. U. H., Karim M. A. (2019), Development of a porosity prediction model based on shrinkage velocity and glass transition temperature, Drying Technology, 35, pp. 1988-2004
[13] Rahman, M. M., Gu, Y. T., Karim, M. A. (2018), Development of Realistic Food Microstructure considering the Structural Heterogeneity of Cells and

Intercellular Space, Food Structure, 15, pp. 9-16

[14] Blikra M. J., Skipnes D., Feyissa A. H. (2019), Model for heat and mass transport during cooking of cod loin in a convection oven, Food Control, 102, pp. 29-37

[15] Karim, M. A., Hawlader, M. N. A. (2005), Mathematical modelling and experimental investigation of tropical fruits drying, International Journal of Heat and Mass Transfer, 48(23-24), pp. 4914-4925

[16] Sing R. P., Heldman D. (2008), Introduction to Food Engineering, Esliver, Academic Press, Ch 04

[17] Mills, A. F. Basic Heat and Mass Transfer. Massachusetts: Irwin; 1995

[18] Yadav K.K., Grang N., Verma A. K, (2017), Optimization and extraction of oil from mango seed kernel (Mangifera indica), Indian Journal of Agricultural Sciences, 87(7):943-946 